\title{
Migration and global environmental change: methodological lessons from mountain areas of the global South
}

\author{
A. Milan ${ }^{1}$, G. Gioli ${ }^{2}$, and T. Afifi ${ }^{3}$ \\ ${ }^{1}$ Institute for Environment and Human Security, United Nations University, Bonn, Germany \\ ${ }^{2}$ Institute of Geography, CLISEC - University of Hamburg, Hamburg, Germany \\ 3 independent scholar \\ Correspondence to: A. Milan (milan@ehs.unu.edu)
}

Received: 06 November 2014 - Published in Earth Syst. Dynam. Discuss.: 10 December 2014
Revised: 27 May 2015 - Accepted: 02 June 2015 - Published: 22 June 2015

\begin{abstract}
The relationship between migration and environmental and climatic changes is a crucial yet understudied factor influencing mountain livelihoods in the global South. These livelihoods are often characterized by high prevalence of family farming, widespread dependence on natural resources, and high sensitivity to climatic changes. Except for a limited number of empirical case studies, the literature on migration and global environmental change has not yet moved beyond case study results to address and explain global patterns and specificities of migration in mountain areas of the global South. After an introduction to the topic, the authors present a new synthesis of three field studies combining household surveys, participatory research approach (PRA) tools and key informant interviews in Pakistan, Peru, and Tanzania. This article suggests that the systematic use of transdisciplinary approaches, with a combination of quantitative and qualitative empirical methods, is the key to understanding global migration patterns in rural mountain areas of the global South. The results of our synthesis suggests that survey data should be triangulated with PRA results as well as secondary data in order to build household profiles connecting vulnerability (measured through a multidimensional index) with human mobility patterns. Such profiles can be conducive to better understand the feedback processes between livelihoods and mobility patterns both within each case study and across case studies, helping researchers to draw general lessons.
\end{abstract}

\section{Introduction}

\subsection{Migration and environmental change in the context of climate change}

Research on the interaction between migration and global environmental change dates to the late 19th century, when many of the "founders" of migration studies (Ratzel, Semple, Ravenstein, Huntington, and Kropotkin) included environmental and climatic considerations among the determinants of migration decision-making (Piguet, 2013).

However, the environment has disappeared from the migration debate for most of the 20th century, only to reappear around the end of the same century when climate change became a key scientific and political topic (HM Treasury, 2006; IPCC, 2007). In fact, the First IPCC Assessment Report highlighted that the single greatest impact of climate change could be on human migration (Tegart et al., 1990).

The initial framing of the debate in the 1990s focused predominantly on whether environmental drivers per se could determine human mobility patterns, and on estimating figures of potential (climate refugees) (often portrayed as a security threat) in future climate change scenarios.

While different terms and definitions have been used by different authors, forecasts on the number of environmental/climatic migrants ("refugees", in the definition of some authors) by 2050 varied from 50 to 350 million. The most widely cited estimate was provided by Myers, who predicted 
200 million potential environmental migrants by 2050 (Myers, 1993, 1997, 2002; Nicholls, 2004; HM Treasury, 2006; Suhrke, 1994). These estimates continue to capture media headlines, fuelling imagery of a future world flooded by climate refugees forced to move because of an increasingly hostile and resource-scarce environment.

However, hosts of subsequent studies have cast serious doubts on the reliability of such estimates which were mostly based on the number of people living in places at risk without factoring in the degree of resilience and adaptive capacity of affected communities. Moreover, these estimates ignored the multi-directional and often temporary nature of migration as well as the inherent complexity of the decision to migrate (IPCC, 2007).

In the recent literature, a broad academic agreement has emerged on five key points regarding the relationship between migration and environmental change in the context of climate change:

- Environmental change will have an increasing impact on migration in the future through its interrelationship with other demographic, economic, political, and social drivers of migration (Foresight, 2011). Hence, migration decision-making is always complex and researchers should be careful in establishing any direct relationship between climatic and environmental stressors and migration (Afifi, 2011; Bettini, 2013; Mortreux and Barnett, 2009; Piguet, 2012; Wrathall, 2012).

- Most migration related to climatic and environmental factors is and will be internal rather than international, with the notable exception of border areas (including mountains) and small states (particularly small island developing states) (Hugo, 1996).

- While migration is often understood and framed as a failure to adapt to climate change, it can also be part of positive adaptation strategies (Bardsley and Hugo, 2010; Black et al., 2011b; McLeman and Smit, 2006; Tacoli, 2009).

- In the upcoming decades, millions of people who would like to move might be unable to leave locations in which they are vulnerable to environmental change (Black et al., 2013).

- Existing legal protection gaps should be filled, especially in the case of or people displaced across borders in the context of disasters and the effects of climate change (Kälin, 2012).

In spite of these points of agreement and an increasing number of theoretical and empirical publications on migration and environmental and climatic changes, the knowledge base remains uncertain. Aside from the inherent complexity of the nexus of environmental and climatic changes and migration, different scientific communities (from the disaster reduction risk to the migration and development communities and the climate and environmental science scholarship) have looked at the issue through their specific disciplinary lens. This has led to a general lack of holistic theoretical and empirical approaches, which is paramount for both research and policy design.

In this context, mountains are a blank spot in terms of academic research and available data on both their hydroclimatology and societal responses to climatic and environmental change, including human mobility.

\subsection{Climate change and its societal impacts in mountain areas of the global South}

Climatic variability - along with extreme weather events impacts particularly resource-dependent societies, affecting both assets and livelihoods. These issues are exacerbated in regions in socioeconomic transition and political instability, so that many of the identified hotspots of climate change are located in the global South, where higher degrees of exposure and sensitivity are often accompanied by a limited adaptive capacity, high levels of poverty, weak institutions and conflict.

Within resource-dependent areas of the global South, mountain areas are particularly vulnerable to the adverse effects of climate change because of their high sensitivity to climatic changes and high prevalence of (often rain-fed) family farming in marginal and harsh areas (Beniston, 2003; IPCC, 2013, 2014; Jodha, 1992; Messerli et al., 2004).

Mountain areas comprise approximately $20 \%$ of the Earth's surface, they are home to roughly $10 \%$ of the world's population, and they supply about $50 \%$ of the world's population with major natural resources including water, energy, minerals, forest and agricultural products. Moreover, they are key storehouses of biological diversity, natural habitats for endangered species, and an indispensable part of the world's ecosystem (Godde et al., 2000; Smethurst, 2000; Viviroli et al., 2007).

The Fifth Assessment Report of the Intergovernmental Panel on Climate Change (IPCC AR5) points out major adverse impacts of climate change on mountain areas worldwide and particularly on precipitation, glaciers, snowfall, permafrost, and ice cover (2013, 2014). Rising global temperatures contribute to changes in species distribution (Pounds et al., 1999); rainfall variability and extreme rainfall events (Dore, 2005); and snow cap melting (Hock, 2003). Glacial melting and high rainfall can in turn lead to intensive floods and landslides (Evans and Clague, 1994); higher amount of debris flows and avalanches (Beniston, 1994); and other potential hazards which impose major threats to the ecosystem and great damages to the infrastructures, communication networks, farm productivity and local economy (Beniston, 1994).

The interaction of climatic and environmental changes with other drivers of livelihood change in mountain areas 
(such as population dynamics and economic globalization) is of the greatest importance yet it is relatively understudied (IPCC, 2013; Jodha, 1992; Messerli et al., 2004). In particular, the relationship between migration and environmental and climatic changes is a crucial driver of livelihood dynamics which has barely been studied in a systematic way (Kollmair and Banerjee, 2011; Skeldon, 1985).

\subsection{Past empirical approaches to study migration and environmental change in mountain areas of the global South}

\subsubsection{Quantitative studies}

From an empirical point of view, most quantitative studies on migration and the environment in mountain areas have taken two approaches: either using existing population and environmental data from different sources or designing a new survey to collect them through a case study approach (Bilsborrow and Henry, 2012).

A good application of the first approach is provided by the Chitwan Valley Family Study (CVFS) in the Terai belt of Nepal (situated at the foothill of the Himalaya). The CVFS spans over 108 months (between 1997 and 2006) and includes a total of 1583 household surveys, 5271 individual interviews (with life histories), land use measurements for each neighbourhood, and a monthly registry of demographic events. The database has been analysed applying descriptive and inferential statistical tools as well as modelling migration through discrete time event history methods (Bhandari, 2004; Massey et al., 2010).

However, past survey data can only be used when a comprehensive database with information on demographic, migratory and environmental issues is available. Given the remoteness and isolation of mountain areas and the lack of reliable data, the chances of successfully replicating this method are presently limited.

More often, researchers have designed a new survey to answer specific research questions within case studies (Ezra, 2003; Gray, 2009; Gray and Bilsborrow, 2013, 2014). While individual sample surveys can be tailored very well to specific contexts (Piguet, 2010), they have rarely been used to look at migration in mountain regions of more than one country.

The Where the Rain Falls (hereafter Rainfalls) case studies in mountain areas of Guatemala, Peru, and Tanzania (the latter two to be presented later in this article) are an exception. Similarly, the case study of Pakistan presented here has followed the approach developed by the International Centre for Integrated Mountain Development (ICIMOD) in the project entitled Too much water, too little water - Adaptation strategies to climate induced water stress and hazards in the greater Himalayan region (2008-2011), which looked at the role of labour migration in communities affected by the impacts of too much (flash and other floods) and too little (drought and water shortage) water in four countries of the Hindu Kush-Himalaya (HKH) region (China, India, Nepal, and Pakistan) (Banerjee et al., 2011, 2013).

\subsubsection{Mixed methods}

The relationship between population dynamics and the environment in mountain areas of the global South is complex and cannot be easily captured by quantitative surveys alone. While empirical studies relying exclusively on qualitative methods are rare (Kaenzig, 2015), most researchers use a mix of quantitative methods (especially survey data) and qualitative data (ethnographic methods).

There are two most common combinations of quantitative and qualitative data. Firstly, household surveys are often complemented by in-depth individual interviews (Goodall, 2004). Secondly, as shown in the three case studies presented in this article, survey data can be combined with key informant interviews and participatory research approach (PRA) tools (Banerjee et al., 2013; Milan and Ruano, 2014).

\subsection{Contribution of this article}

In the case studies, the authors built household profiles linking household vulnerability with human mobility patterns which helped explain the role of migration in household attempts to manage risks in areas where they are highly vulnerable to environmental and climatic stressors. In particular, they provide insights into households which will likely use migration to enhance their resilience; those that will likely migrate but for which it is an erosive (to their resiliency) and undesirable action indicating constraints or limits to adaptive capacity in situ; and those who cannot move, even if they "would like to" (Gioli et al., 2014, p. 263; Warner and Afifi, 2014, p. 11).

While these household profiles, built as an ex post exercise, provided important insights and lessons learned for the future, the authors suggest in the discussion that transdisciplinary teams should aim at building household profiles based on multidimensional vulnerability indices from the onset of the research. Such profiles should be used as a lens through which researchers study the relationship between socioeconomic status and different forms of mobility both within and across different case studies, especially in the case of rural mountain areas of the global South, which are highly sensitive to climate change and where isolation, lack of demographic data and scant distribution of meteorological stations present a specific set of challenges.

\subsection{Theoretical background of the case studies}

The theoretical background of the case studies presented below is the New Economics of Labour Migration (NELM) (Stark and Levhari, 1982; Stark and Bloom, 1985). Migration is hence understood as a risk management strategy adopted 
at the household level, and the main question addressed is "under what circumstances do households use migration as a risk management strategy when facing rainfall variability (Sects. 2 and 3), environmental shocks (Sect. 4) and food insecurity?".

Such a question calls for a deeper understanding of the livelihood and environmental context, and this is why the NELM theory was supplemented by the sustainable livelihoods approach (SLA) which allows one to explore the asset base of households, divided into natural, physical, financial, human, and social assets that are complementary to each other (Banerjee et al., 2013; Carney, 1998; Kollmair and Gamper, 2002; Kniveton et al., 2008).

\section{The Rainfalls Peru case study}

\subsection{Methodological approach}

The Peru case study of the Rainfalls project was conducted in fall 2011 in three mountainous communities located in the central part of the Mantaro Basin: Acopalca, located at $3900 \mathrm{~m}$ a.s.l. (metres above sea level), Chamisería (3583 m a.s.l.) and Paccha (3260 $\mathrm{m}$ a.s.l., but approximately half of its inhabitants share communal grazing land at higher altitudes). These communities belong to the region of Junín, in the Central Highlands of Peru and they are all within less than $30 \mathrm{~km}$ from the commercial city of Huancayo (see Fig. 1).

The research site was selected using three main criteria:

- population highly vulnerable to rainfall variability and bad weather (prevalence of rain-fed agricultural activities);

- high percentage of people living in conditions of poverty;

- high prevalence of migration.

Following the Rainfalls research protocol, the team conducted 150 household surveys, 23 PRA sessions with a total of almost 150 participants, and 14 semi-structured expert interviews at the national, regional, and local level.

The survey focused on three main variables: rainfall variability, food insecurity, and human mobility, without overlooking other economics, political, social, cultural, and demographic factors. Surveyed households were identified through simple random sampling.

The PRA sessions included participatory socioeconomic and environmental mapping, seasonality calendars, focus group discussions, timeline and trend analysis, livelihood risk ranking, Venn diagrams, and mobility maps.

Expert interviews were based on a comprehensive list of open questions on the following variables: climate change and rainfall variability; livelihood and food security; migration; and the connections between these variables. During each interview, only a selection of relevant questions was used. The research team interviewed representatives

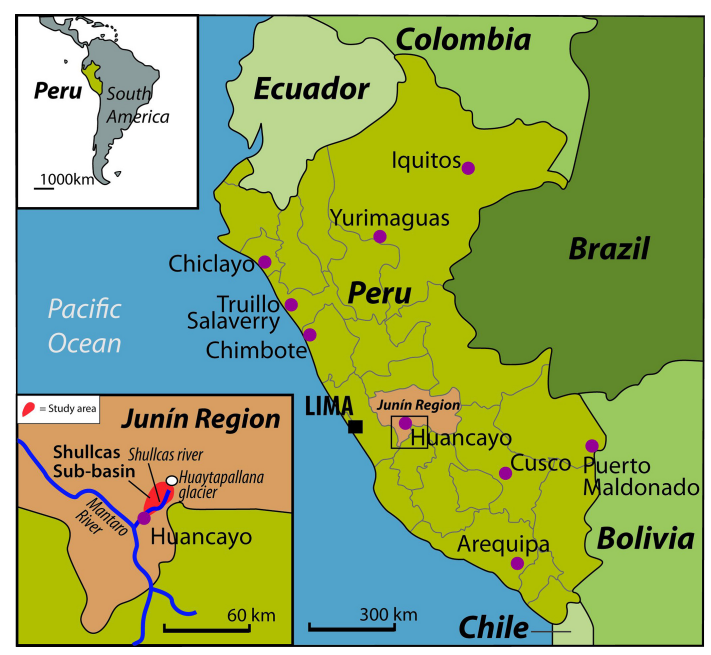

Figure 1. Location of the Rainfalls Peru research site. Source: Milan and Ho (2014; their Fig. 1).

from several ministries and governmental agencies, international institutions, non-governmental organizations (NGOs) and academics.

Finally, in addition to primary data, the research team used local and national secondary socioeconomic data as well as rainfall data from the Shullcas meteorological station located within the research area at $3750 \mathrm{~m}$ a.s.l.

The Rainfalls research protocol contains more detailed information on the overall project's research approach and methodology (Rademacher-Schulz et al., 2012). In addition to its implementation in Peru and Tanzania (presented in this article), the Rainfalls approach has been used within the project in six other case studies: Bangladesh, Ghana, Guatemala, India, Thailand, and Vietnam (Etzold et al., 2014; Milan and Ruano, 2014; Murali and Afifi, 2014; Rademacher-Schulz et al., 2014; Sakdapoldrak et al., 2014; Van de Geest et al., 2015).

\subsection{From methods to results}

In the first phase, all primary and secondary data were analysed in order to understand the complex interactions between livelihoods and migration patterns in the area. The task proved challenging given the complex nature of local livelihoods, where households often combine rural agricultural activities, urban employment in the nearby city of Huancayo, and different forms of human mobility. While Acopalca, Chamisería, and Paccha were all located within a relatively short horizontal distance (approximately $20 \mathrm{~km}$ ), differences between households located in different parts of the basin were evident, in particular with regards to the relative importance of rural and urban activities and the prevailing forms of human mobility (Ho and Milan, 2012).

As a consequence, after the completion of the case study report, the same authors studied livelihoods and migration 
patterns of households in a comparative way based on higher altitude (highland) and lower altitude (lowland). This ex post exercise had some limitations in terms of survey data: only 114 households could be identified as either lowland or highland, while 33 households from Paccha were excluded from the analysis because of insufficient information for determining their location (Milan and Ho, 2014).

An important component at both stages of the data analysis process was the data triangulation process. For each of the variables of interest, survey data was checked against outcomes of PRA exercises; whenever survey data and PRA outcomes were not consistent, the authors found an explanation for the discrepancy through outcomes of expert interviews as well as secondary data available (including relevant literature).

\subsection{Open questions remaining}

A first open question emerging from this case study is how to better analyse the interaction between migration and specificities of mountain areas such as remoteness and difficult access to market opportunities; the impact of land steepness and land fragmentation; high vulnerability to climate change; glacial melting and water issues; and other specificities which are often hard to measure and to relate to human mobility (Jodha, 1992).

Another interesting area for future investigation both in this research area and in mountain areas in general is the interaction of human mobility with risk of conflicts related to glacial melting and water issues.

Last but not least, Rainfalls focused on the area of origin of migrants. It would be interesting to follow migration trajectories, at least for one or two main migration corridors, in order to understand what determines migration outcomes in areas of destination (Findlay, 2011).

\subsection{Lessons learned}

Methodologically, one of the most important choices in the survey design phase is the trade-off between the necessary survey length for such a complex issue and data quality which tends to decrease as survey length increases. The combination of a short quantitative survey and qualitative techniques seems to be a good compromise.

Moreover, conducting a cross-country comparative survey without losing valuable information about the local context is a complicated task. An interesting approach for combining cross-country comparability and in-depth understanding of the local context, as discussed later in this article, is building household profiles based on socioeconomic characteristics and migratory responses to sudden and slow-onset environmental and climatic events and stressors.

The timing of research also played an important role: research was conducted right after the wettest rainy season on record. As a consequence, people tended to focus their

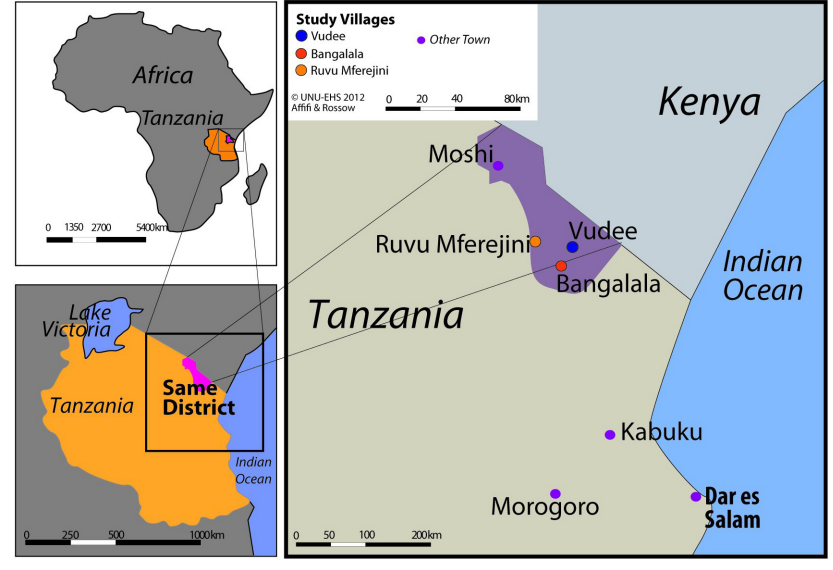

Figure 2. Location of the Rainfalls Tanzania research site. Source: Afifi et al. (2014; their map 1).

answers on issues related to heavy rains, especially in the household survey.

\section{The Rainfalls Tanzania case study}

\subsection{Methodological approach}

Like with the rest of the Rainfalls case studies, a mixedmethods approach combining expert interviews with a 165 household survey and PRA tools was applied in Tanzania. The expert interviews included national and local government officials, NGO representatives, and academics in the fields of migration and climate change, geographers, and meteorologists. Due to the availability of information about household wealth data, it was relatively simple to apply stratified random sampling on households that were classified as poor, medium (wealth), and wealthy. The three research villages were classified according to their altitudes: Ruvu Mferejini (lowland $-655 \mathrm{~m}$ a.s.l.), Bangalala (midland $-900 \mathrm{~m}$ a.s.l.) and Vudee (highland - $1950 \mathrm{~m}$ a.s.l.), all located in the Same District, Kilimanjaro, north-east Tanzania, on the border with Kenya (Afifi et al., 2014) (see Fig. 2).

\subsection{Results}

The methods were applied smoothly in the three villages with few challenges and limitations associated with the field work. These challenges did not vary significantly across the three villages; the researchers faced almost the same challenges regarding the availability of the interviewed households for the entire duration of the interviews as well as the conflicts of interests among the PRA participants. The lack of local data linking weather changes to migration flows in the three villages were - to the extent possible - compensated for by information gathered from the household survey and the PRA sessions. 
However, there was an agreement among meteorological experts, survey respondents, and PRA participants about the fact that the total amount of annual rainfall has not decreased significantly throughout the past 3 decades. Nevertheless, large amounts of rainfall over only a limited number of days throughout the year, resulting in crop failure. Hence, it is the intensity and distribution of the rain over time that affect livelihoods. Based on the PRA outcomes, rainfall variability (increase in drought incidences, seasonal shifts, and prolonged dry spells) and water shortage are the most important threats to livelihood, and hence, influence the migration decision.

Elevation also plays a role in determining the migration patterns across the three villages; Vudee (highland) is the village with the lowest records of migration. The reason for this could be the highest precipitation level (successful subsistence agriculture) and the fewest landholdings of its inhabitants (least means for migration) as compared to the rest of the villages. In addition, Vudee has the highest average years of schooling and the most teachers (no need to send the children to schools outside the village). The immobility can also be attributed to Vudee's highest number of elderly. The extreme opposite is represented in the lowland village Ruvu Mferejini with the most landholdings and the lowest precipitation. Not only would its inhabitants be relatively mobile due to these two factors (more resources and means to outmigrate and stronger reasons to seek water resources elsewhere), but also to its closeness to urban areas. This creates pull factors for inhabitants seeking new jobs. Moreover, this is the village with the highest ratio of pastoral communities (highest percentage of people dependant on livestock activities of the three villages), which are always more sensitive to water availability. It is worth mentioning that the high number of landholdings of this village could be an outcome of the remittances that in turn support young people in the communities to seek education elsewhere. Moving to Bangalala, the midland village, it lies between the two other villages regarding all the factors mentioned above.

\subsection{Open questions remaining}

There are a few open questions remaining after the field research and the analysis of its outcomes: it is not clear how the communities will deal with climatic problems in the future, especially that these seem to have intensified throughout the past few decades. This might not be an issue in the highlands where the precipitation is relatively high and the infrastructure allows the communities to survive without needing to move to other areas. However, in the lowlands, it is important to consider the migration patterns more closely and to find out whether short-term and seasonal migration would turn into long-term or even permanent migration, given the increasing frequency of droughts and dry spells. Permanent out-migration, especially among the youth, would imply less labour in the areas of origin and would hence lead to ne- glecting agricultural activities with all the negative effects on vegetal cover and soil.

One other question the research was not able to answer is to what extent villages with different altitudes interact in terms of human mobility and whether there are migration flows between these villages with all the implications on labour and landholdings. For example, it is clear that Vudee (highland) has the lowest records of out-migration, but the researchers did not know whether it received migrants from mid- and lowland villages, such as Bangalala or Ruvu Mferejini, who might want to benefit from the high precipitation and improved education, instead of moving downwards to urban areas. This might be an option for Vudee, given that the number of elderly is the highest among the three villages and "pumping" new labour into it would be beneficial for the village in general.

\subsection{Lessons learned for the future}

Since the field research period was a total of 3 weeks in one particular season, the researchers sensed the need of visiting the same research site more than once and staying longer during each visit in order to capture more detailed and nuanced insights into its dynamics, especially since the most important variable they were looking at was rainfall variability. Therefore, future research should consider the number of visits and its duration.

Since polygamy is widespread in the research site, it was often a challenge to find out which household representative to interview in the case of the absence of the household head. It might be useful to design the questionnaires in the future, such that this factor is considered and where a set of questionnaires could accommodate more than one household in the case of polygamy.

It might also be useful to compare between villages on the same altitude but in different areas/regions rather than comparing between villages of different altitudes in the same area/region. This might help the villages under similar circumstances learn from each other, especially when it comes to coping strategies in response to rainfall variability.

\section{The Pakistan case study}

\subsection{Methodological approach}

Like the Rainfalls project, the present case study employed a mixed-methods approach combining expert interviews with 210 household surveys and PRA tools (including 31 interviews with key informants at the community and national levels, and 6 gender-disaggregated focus group discussions with 8 to 10 people). The fieldwork was carried out in the Gilgit-Baltistan region of Pakistan, covering six villages of the western Karakoram (altitude ranging between 1800 and $2760 \mathrm{~m}$ a.s.1.) in the Hunza and Yasin Valleys (see Fig. 3). Both valleys have an arid climate, where agriculture depends 


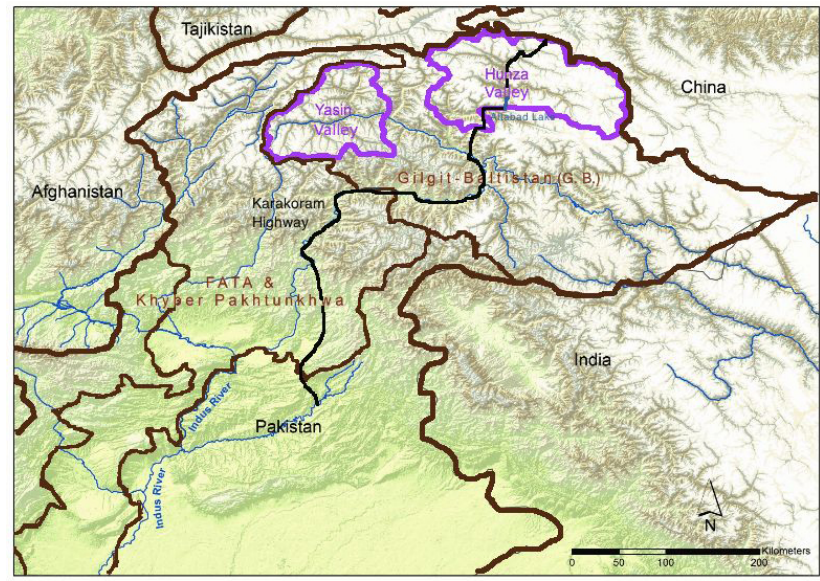

Figure 3. Location of the Pakistan research site. Source: Gioli et al. (2014) (Fig. 1).

on indigenous irrigation systems channelling meltwater directly from glaciers to the bottom of the mountain slopes. The two valleys have faced similar challenges and used similar strategies, following the same model of development (implemented by the Aga Khan Rural Support Program) ${ }^{1}$. Nonetheless, their level of development diverges, as suggested by various socioeconomic indicators such as literacy and the average per capita income which is USD 160 in Yasin and USD 340 in Hunza (Gioli et al., 2014, p. 259).

The study area lies in the upper Indus Basin (UIB), where the observed climate trends are anomalous: as opposed to the climate change signal experienced in the Himalaya, the UIB has experienced cooling trends in the summer season for decades, non-statistically significant trends of annual temperature, and increasing or stable precipitation throughout the year (Archer and Fowler, 2004; Fowler and Archer, 2006; Khattak et al., 2011; Bocchiola and Diolauiti, 2013), accompanied by mass gains in the glaciers of the region (Bolch et al., 2012; Hasson et al., 2014). The survey considered two major environmental shocks: the 2010 flood (Yasin) and the massive 2010 landslide, which blocked the Hunza River and created Attabad Lake. The lake submerged houses, agricultural land, and infrastructure, including part of the vital Karakoram Highway. While the two events considered are not a direct result of climate change, they are assumed to be a proxy for future more severe natural hazards resulting from climate change. The household survey aimed at collecting data on (1) the local perceptions of changes in climate patterns and natural shocks; (2) the impacts of climate change and variability on households' productivity, livelihood secu-

\footnotetext{
${ }^{1}$ The Aga Khan Rural Support Program (AKRSP) is a branch of the Aga Khan Development Network (AKDN) that has pioneered rural development in Gilgit-Baltistan. Since the 1980s AKRSP has introduced cash crops such as potatoes and developed orchards (e.g. of almonds, apricots, and grapes), which have become a major source of income for local people.
}

rity, and main adaptation strategies, and (3) the role of migration in the context of environmental change and its gendered impacts. The households were randomly selected in each village by random walks, representing about $12 \%$ of the estimated number of households per village.

\subsection{Results}

The study has found a high degree of convergence between climatic data and the local narratives of change collected in the survey (Gioli et al., 2013). Over the last 10 years, climate change and variability are perceived as negatively affecting nonagricultural productivity by over $85 \%$ of the surveyed households, and "Low temperatures", "Erratic rainfall", "Flood", and "Landslide" are indicated as the top causes. As for the responses to climate change and variability, the study highlighted that most households resorted to coping mechanisms to ward off immediate risks rather than proactive adaptive strategies. In the sample, labour migration emerges as an important means of livelihood and is undertaken by $76 \%$ of the surveyed households. Migration occurs predominantly at provincial $(50 \%)$ and national scales (97\%), from rural to urban areas, and is predominantly seasonal and circular, towards trade hubs in the region or to major cities within the country (especially to Karachi). Migration peaked in 2010 - the year in which the two considered environmental shocks took place - with $34 \%$ of all the migrants' first migration occurring during 2010-2012 over a period spanning from 1985 to 2012.

Some interesting patterns emerged from the analysis of the migratory behaviour of a subset of households (17\%) constituted by those who lost all or most of their land $\left(<15 \% /<1500 \mathrm{~m}^{2}\right.$ land remaining) as a result of the 2010 environmental shocks. This group is comprised of extremely poor and vulnerable households whose average income is about half of the mean of the whole sample, and even lower than the average income of 10 years ago. The analysis of the survey data pertaining to this subsample (and substantiated by PRA) generated three distinct household profiles in relation to the use of migration in response to the 2010 environmental shocks (see Fig. 4): (1) those unable to move (36\%), due mostly to the lack of financial resources, employable skills, human capital, or to family obligations and illnesses. The 2012 income of these households was found to be about $60 \%$ less than that of those who lost land but were able to resort to labour migration (the second and third groups below). Interestingly, 10 years ago the incomes were homogenously distributed in the subsample. The inability to migrate is hence positively correlated to the possibility of falling into the poverty trap; (2) those who undertook migration ex post (25\%) in 2010 to cope with losses and damages in the wake of environmental shocks (Warner and van der Geest, 2013). In 2012, this group earned $30 \%$ more than those who did not migrate. However ex post migration might prove detrimental in the medium or longer term, as it erodes important assets 

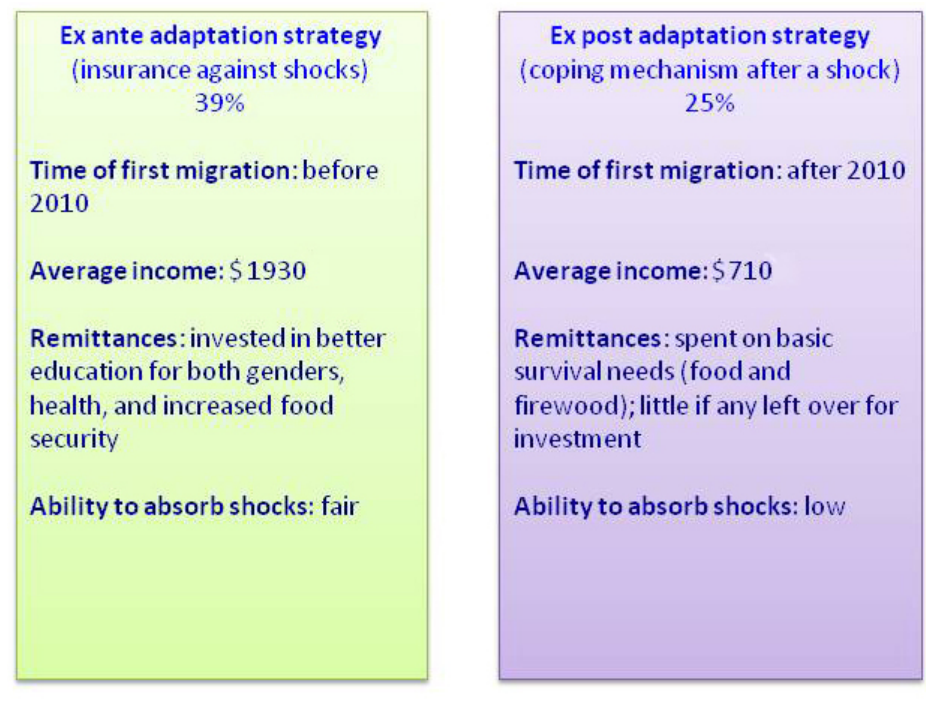

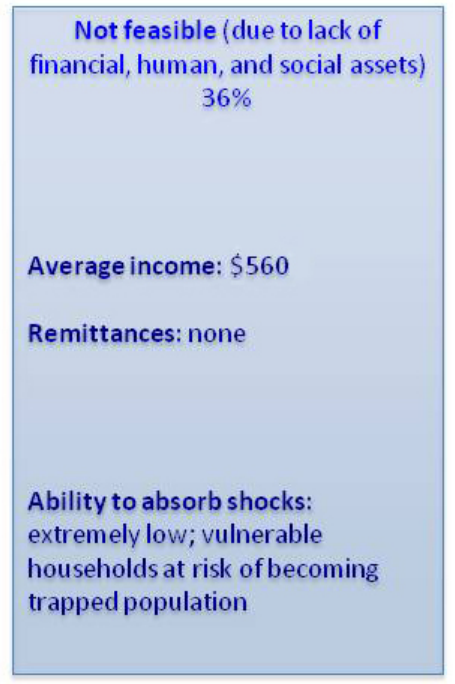

Not feasible (due to lack of $36 \%$

Resilience

\section{Vulnerability}

Figure 4. Household profiles highlighting the role of migration in households deprived of all or most arable land after the 2010 environmental shocks. Source: Gioli et al. (2014) (Fig. 3).

and decreases the household's overall resilience; (3) households (39\%) whose first migration took place before 2010 (mostly in the 2000s). This group has substantially increased its income which is now more similar to the average of the whole sample, showing that migration as ex ante risk mitigation strategy is the most successful form of mobility.

\subsection{Questions remaining open}

The observed changes of the hydro-climatology of the surveyed area over the last few decades present peculiar features as compared to the rest of the HKH region. The scientific reasons behind such anomalous behaviours are still being debated and it also remains unclear whether such anomalies will persist in the near future. Until now, besides diversifying livelihoods, local people have resorted to several coping measures and in the sample, the shift of the agricultural calendar in response to cooler summers, reduced river flow, and erratic precipitation was the most commonly adopted measure (Gioli et al., 2013).

Pakistan has the highest urbanization rates of any country in South Asia, and future demographic scenarios are paramount for policy and highly uncertain (the last national census was held in 1998). Improved education for both genders is triggering rural-to-urban movements, and GilgitBaltistan fares slightly better than the national average at almost every level of education in terms of female school enrolment (USAID, 2011). The surveyed communities, especially Hunza, fare particularly well within the region, and the increase in highly educated men and women in the region presents both a challenge and an opportunity. It is not clear to what extent in situ opportunities will arise for taking advantage of the human capital and start a virtuous cycle of development and gender-positive transformation.

Another aspect of uncertainty is the institutional status of the target area. The region is remote and institutionally marginalized within Pakistan ${ }^{2}$. The proper integration of the region within the state of Pakistan would indeed contribute to reducing its volatility and to sustaining mid- and long-term plans for adaptation and climate-smart rural development.

\subsection{Lessons learned for the future}

The desk review of relevant local literature and expert interviews took place in Islamabad and Lahore over a period of 2 months. However, the lack of available socioeconomic, geographical, and geophysical data (due to its special constitutional status, the region is not included in official statistics) have limited the quality of the design of the survey, as well as the ability to interpret the obtained data. Future research should integrate surveys on migration with information on land cover and its changes obtained through satellites to enhance understanding of, for instance, how changes in agriculture affect migration and vice versa. The research team fully appreciated the benefits of such an interaction,

\footnotetext{
${ }^{2}$ In August 2009, the region gained self-rule and was granted the locally elected Gilgit-Baltistan Legislative Assembly, obtaining a de facto but not constitutional province-level status within the country.
} 


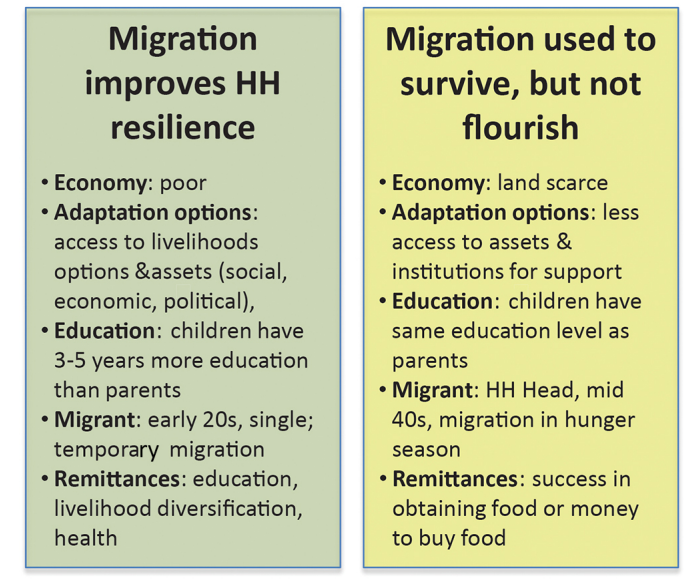

Resilience to climatic stressors

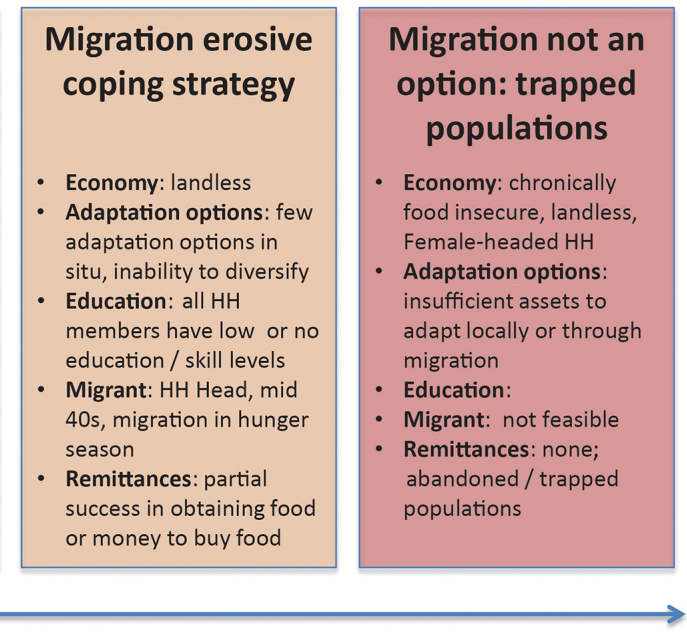

Vulnerability to climatic stressors

Figure 5. Household $(\mathrm{HH})$ profiles affect whether migration is adaptive or erosive vis-à-vis rainfall, food, and livelihood insecurity. Source: Warner and Afifi (2014) (Fig. 2).

as an extensive investigation of seasonal snow cover in the study area (Hasson et al., 2014) was driven by both meteorological observations and local perceptions researched during the present study. The integration of advanced remote sensing (RS) and geographic information system (GIS) techniques with mixed methods and micro-scale approaches to livelihoods and communities' perceptions will significantly help in better understanding the vulnerabilities, quantifying the risks, and mapping the capabilities of the local communities, and could greatly enhance understanding of mobility in the context of global environmental change.

Due to the remoteness and security challenges, as well as to lack of resources, the actual fieldwork in Gilgit-Baltistan was completed in 18 days (in June 2012), and the area of Astore (initially in the plan) had to be dropped. The surveyed communities are very cohesive and ethnically homogenous. It would have been extremely useful to have surveyed at least one community within the region facing similar environmental challenges but characterized by a different social composition and economic indicators.

In the future, more attention shall be devoted to the selection of control groups in order to better assess the role played by several socioeconomic variables in determining the availability and the success of migration as a livelihood diversification strategy in the context of environmental change.

\section{Comparative results and discussion}

\subsection{Household profiles}

\subsubsection{Lessons learned from the three case studies}

Beyond its single case studies, the Rainfalls project offered interesting insights into how to move methodologically from case-study-specific results to cross-country results through the profiling of households in terms of their socioeconomic characteristics and migratory dynamics (Fig. 5). It would be interesting to conduct a similar exercise for several studies in different mountain ranges worldwide.

The profiles used in this article have been employed to enhance the understanding of migration patterns as they relate to both long-term processes, such as rainfall variability (Peru and Tanzania), and short-term shocks, such as floods and landslides (Pakistan).

The households' typology helped identify two main processes of positive feedback in both studies. On the resilient side of the spectrum, more assets allow for more livelihood diversification (including migration), which in turn produces more assets and increases the resiliency of the household. On the vulnerable side, a positive feedback process is found again, but one leading to the so called "poverty trap": the most vulnerable households (e.g. female headed households, those lacking human capital) enter a self-reinforcing mechanism which causes poverty to persist. In some cases, these households are not only economically trapped, but they might also be financially trapped as they do not have the resources to migrate and, in times of hazardous events, they will not be able to utilize mobility as an adaptive strategy (Milan and Ruano, 2014).

The authors warn that reality is not as unambiguous as their classification and it is not always possible to draw a clear cut between "vulnerable" and "resilient" households or between "erosive" and "adaptive" migration, as the process is dynamic and households and migrants move between the various circumstances (Warner and Afifi, 2014). Nevertheless, the isolation of these two processes was important, as it provided a heuristic typology and a lens through which re- 
searchers could look at the role of migration in specific environmental settings and conditions through more comprehensive and comparable research.

\subsubsection{Future research: building profiles through a multidimensional vulnerability index}

The three case studies presented here were derived from an ex post data analysis, but the profiles could become the hypotheses to be tested in the next generation of research on migration and global environmental change in mountain areas of the global South. Researchers from different academic disciplines should work closely with practitioners in order to build household profiles based on a solid multidimensional vulnerability index, where both the key dimensions of vulnerability and the thresholds for their indicators properly represent the socioeconomic reality as well as human mobility patterns.

While the use of multidimensional indices in the poverty (Alkire and Foster, 2011) and livelihoods (Hahn et al., 2009) literature is widespread, its possible use on human migration is promising yet understudied (Siegel and Waidler, 2012; Loschmann and Siegel, 2014), and no attempt has been made to link a multidimensional vulnerability index to human mobility patterns in mountain areas of the global South.

On one hand, such an index would build on the lessons learned from the poverty and livelihoods literature, both from a theoretical perspective (in which dimensions of vulnerability should be considered) and an empirical point of view (in which indicators and thresholds allow researchers to build effective profiles that can be conducive for case-study-specific in-depth understanding and for comparability).

On the other hand, the index should take into account the specificities of local livelihoods in resource-dependent mountain areas, such as the importance of livelihood diversification, preventive measures against climatic and environmental hazards, and housing conditions.

Such profiles would contribute to the academic debate on migration and environmental change in several ways; firstly, they would help overcome the inherent tension between much-needed site-specific research digging deeply into a particular real-world scenario (with a combination of quantitative methods and ethnographic and PRA methods) and generalizations conducive to comparability and general lessons for policy makers.

Secondly, drawing on poverty economics, these household profiles could help integrate migration (usually neglected in the microeconomics of poverty or understood as negative) into studies of micro-dynamics of adaptation to climatic and environmental changes at the household/community level. Thirdly, they could act as a bridge for better integrating migration research with community-based adaptation methodologies.

For instance, the role of gender and ethnicity in shaping the differentiated and interdependent adaptive options available to men and women has been increasingly acknowledged (Adger et al., 2009; Nightingale, 2009; Onta and Resurrecion, 2011; Verma et al., 2011). Whereas the wider adaptation scholarship recognizes the role of entrenched inequalities at the intersection of gender, class, ethnicity, religious affiliation, caste, etc. in shaping adaptive responses, the literature on migration and global environmental change still lacks the proper integration of these elements. In the case of mountain areas, the case study of Pakistan has explicitly looked into gender dynamics and Massey et al. (2010), in their CVFS study, show that the effects of environmental change vary by gender and ethnicity, with women being more affected by changes in the time required to gather fodder and men by changes in the time gathering firewood, and high-caste Hindus generally being less affected than others by environmental change.

\subsection{Way forward: further methods for transdisciplinary research on migration and global environmental change}

The Pakistani case study has highlighted the potential of integrating RS in the research design. Brandt et al. (2014) investigated interactions between changes in temperature, rainfall patterns and vegetation trends by combining GIS methods with in-depth field work at the local scale. The combination of macro-scale top-down approaches (GIS and RS) and bottom-up mixed methods to develop household profiles could greatly enhance our understanding of migration in the context of climatic and environmental changes, in particular if such approaches are not just merely juxtaposed but codesigned beginning at the outset of the research.

Regarding methodologies for simulating possible future migration patterns under different climatic and environmental scenarios, agent-based modelling seems to be the most promising approach (Kniveton et al., 2011; McLeman, 2012; Piguet, 2010; Smith et al., 2008). An agentbased model (ABM) is a computational simulation of the behaviour of human agents (individuals and/or households) as well as their interactions with each other and the environment. Within such models, agents can learn, adapt, and modify their behaviour depending on the circumstances they face, and their subjective norms on attitudes towards migration can change over time (Bonabeau, 2002; Janssen and Ostrom, 2006; Kniveton et al., 2012; Smith, 2014).

A further methodological addition could be made by complementing monitoring of monthly migratory movements with a demographic database and with genealogical charts which offer very interesting insights into long-term migratory dynamics (Umezaki and Ohtsuka, 2002).

Last but not least, a comprehensive framework of analysis enabling the overcoming of a reductionist and "naturalized" understanding of the socioeconomic drivers of vulnerability is still missing in the migration and global environmental change scholarship. 
In recent years, academics have tried to overcome the disciplinary isolation and reductionism of climate change, and migration scholarship through interdisciplinary approaches (McAdam, 2010). Nevertheless, knowledge on the field of climate change, environmental change and migration is still uncertain and the concrete nature of the problem is disputed (Bettini, 2013; Bettini and Andersson, 2014; Nicholson, 2014), conditions which call for a truly transdisciplinary approach rather than just interdisciplinary approaches (Klein et al., 2001; Hirsch Hadorn et al., 2008).

In particular, the case studies presented in this article confirm that survey data should always be combined with PRA tools, a cornerstone of transdisciplinary research, understood as an approach based on collaboration with local people that takes in account their rich knowledge and their perceptions of the problem.

\section{Conclusions}

Over the last few years, the theoretical debate on migration and global environmental change has moved forward substantially (Black et al., 2011a). The literature would also benefit from more systematic transdisciplinary empirical approaches, and a widespread use of mixed quantitative and qualitative methods (Obokata et al., 2014; Piguet, 2010; Warner, 2011a, b).

There are three main reasons why we believe transdisciplinary approaches and multidimensional vulnerability index-based household profiles have great potential for the advancement of the literature on migration patterns in the context of environmental change both in mountain areas and elsewhere.

Firstly, in an increasingly mobile world, accounting for the timing, conditions, and costs of migration across different socioeconomic household profiles is a crucial step for a comprehensive livelihoods assessment. This can also be the first step to assess through time-series analysis under which circumstances migration can be considered as a positive process contributing to livelihood resilience rather than a detrimental process.

Secondly, studying rural livelihoods through the systematic use of socioeconomic and migratory profiles would allow for drawing general lessons based on relative considerations. It would be interesting to understand whether households in relatively similar conditions within their socioeconomic and environmental context in different areas of the world tend to also follow similar migration patterns.

Thirdly, building household profiles with a transdisciplinary approach could help embed wider developmental concerns and indicators into research on population/environment interactions, in particular on how socioeconomic differences shape the migration process itself and the relationship between mobility and immobility (who is able to move, where to, and at what price) in different contexts. This transdisciplinary work will help to understand migration as integral part of wider developmental process rather than as an outcome of poverty or growth.

In conclusion, the authors hope that this article will boost the (still underdeveloped) scientific debate on empirical methodologies to enhance scientific understanding of livelihoods and migration patterns in the context of global environmental change in mountain areas of the global South.

Author contributions. Each author drafted the section on a particular case study: A. Milan - The Rainfalls Peru case study, T. Afifi - The Rainfalls Tanzania case study, and G. Gioli - The Pakistan case study. Moreover, A. Milan drafted the rest of the manuscript which was then enriched with substantial contributions from the coauthors.

Acknowledgements. We would like to thank everyone in the research areas for their participation in the household survey, participatory research group discussions, and expert interviews: we learned a lot from the communities and appreciated their cooperation. We are also thankful to the research teams in Pakistan, Peru, and Tanzania for their great data collection and data entry work. A. Milan and T. Afifi have benefited from the very valuable background work of Kristina Belesova, Noemi Cascone, Beatriz Lopez, and Alice Yiu (UNU-EHS). G. Gioli acknowledges the support of the Integrated Climate System Analysis and Prediction (CliSAP) Cluster of Excellence of the University of Hamburg. Last but not least, all authors are grateful to the participants to the 2013 Hamburg Conference on Climate Change and Environmental Pressure: Adaptation and Resilience of Local Communities in the Hindu-Kush-Himalaya $(\mathrm{HKH})$ for their feedback on the preliminary concept for this paper.

Edited by: A. Turner

\section{References}

Adger, W. N., Dessai, S., Goulden, M., Hulme, M., Lorenzoni, I., Nelson, D. R. and Wreford, A.: Are there social limits to adaptation to climate change?, Climatic Change, 93, 335-354, 2009.

Afifi, T.: Economic or environmental migration? The push factors in Niger, Int. Migrat., 49, e95-e124, 2011.

Afifi, T., Liwenga, E. and Kwezi, L.: Rainfall-induced crop failure, food insecurity and outmigration in Same-Kilimanjaro, Tanzania, Clim. Develop., 6, 53-60, 2014.

Alkire, S. and Foster, J.: Counting and multidimensional poverty measurement, J. Publ. Econ., 95, 476-487, 2011.

Archer, D. R. and Fowler, H. J.: Spatial and temporal variations in precipitation in the Upper Indus Basin, global teleconnections and hydrological implications, Hydrol. Earth Syst. Sci. Discuss., 8, 47-61, doi:10.5194/hess-8-47-2004, 2004.

Banerjee, S., Gerlitz, J., and Kniveton, D.: Labour Migration as a Response to Water Hazards in the Hindu-Kush-Himalayas, International Centre for Integrated Mountain Development, Kathmandu, Nepal, 2011. 
Banerjee, S., Gerlitz, J., and Kniveton, D.: A methodology for assessing patterns of labour migration in mountain communities exposed to water hazards, in: Disentangling Migration and Climate Change, edited by: Faist, T. and Schade, J., Springer, Dordrecht, the Netherlands, 81-100, 2013.

Bardsley, D. K. and Hugo, G. J.: Migration and climate change: examining thresholds of change to guide effective adaptation decision-making, Populat. Environ., 32, 238-262, 2010.

Beniston, M. (Ed.): Mountain environments in changing climates, Routledge, New York, USA, 1-496, 1994.

Beniston, M.: Climatic Change in Mountain Regions: A Review of Possible Impacts, Climatic Change, 59, 5-31, 2003.

Bettini, G.: Climate barbarians at the gate? A critique of apocalyptic narratives on 'climate refugees', Geoforum, 45, 63-72, 2013.

Bettini, G. and Andersson, E.: Sand waves and human tides: exploring environmental myths on desertification and climate-induced migration, J. Environ. Develop., 23, 160-185, 2014.

Bhandari, P.: Relative Deprivation and Migration in an Agricultural Setting of Nepal, Populat. Environ., 25, 475-499, 2004.

Bilsborrow, R. E. and Henry, S. J. F.: The use of survey data to study migration-environment relationships in developing countries: alternative approaches to data collection, Populat. Environ., 34, 113-141, 2012.

Black, R., Adger, W. N., Arnell, N. W., Dercon, S., Geddes, A., and Thomas, D.: The effect of environmental change on human migration, Global Environ. Change, 21, S3-S11, 2011a.

Black, R., Bennett, S. R. G., Thomas, S. M., and Beddington, J. R.: Climate change: Migration as adaptation, Nature, 478, 447-449, 2011b.

Black, R., Arnell, N. W., Adger, W. N., Thomas, D., and Geddes, A.: Migration, immobility and displacement outcomes following extreme events, Environ. Sci. Policy, 27, S32-S43, 2013.

Bocchiola, D. and Diolaiuti, G.: Recent (1980-2009) evidence of climate change in the upper Karakoram, Pakistan, Theor. Appl. Climatol., 113, 611-641, 2013.

Bolch, T., Kulkarni, A., Kääb, A., Huggel, C., Paul, F., Cogley, J. G., Frey, H., Kargel, J. S., Fujita, K., Scheel, M., Bajracharya, S., and Stoffel, M.: The state and fate of Himalayan glaciers, Science, 336, 310-314, 2012.

Bonabeau, E.: Agent-based modelling: Methods and techniques for simulating human systems, P. Natl. Acad. Sci. USA, 99, 72807287, 2002.

Brandt, M., Romankiewicz, C., Spiekermann, R., and Samimi, C.: Environmental change in time series - An interdisciplinary study in the Sahel of Mali and Senegal, J. Arid Environ., 105, 52-63, 2014.

Carney, D.: Sustainable Livelihoods: What contribution can we make?, Department for International Development (DFID), London, UK, 1998.

Dore, M. H.: Climate change and changes in global precipitation patterns: what do we know?, Environ. Int., 31, 1167-1181, 2005.

Etzold, B., Ahmed, A. U., Hassan, S. R., and Neelormi, S.: Clouds gather in the sky, but no rain falls. Vulnerability to rainfall variability and food insecurity in Northern Bangladesh and its effects on migration, Clim. Develop., 6, 18-27, 2014.

Evans, S. G. and Clague, J. J.: Recent climatic change and catastrophic geomorphic processes in mountain environments, Geomorphology, 10, 107-128, 1994.
Ezra, M.: Environmental vulnerability, rural poverty, and migration in Ethiopia: a contextual analysis, Genus, 63-91, 2003.

Findlay, A. M.: Migrant destinations in an era of environmental change, Global Environ. Change, 21, S50-S58, 2011.

Foresight: Migration and global environmental change, Final project report, The Government Office for Science, London, UK, 2011.

Fowler, H. J. and Archer, D. R.: Conflicting signals of climatic change in the Upper Indus Basin, J. Climate, 19, 4276-4293, 2006.

Gioli, G., Khan, T., and Scheffran, J.: Climatic and environmental change in the Karakoram: making sense of community perceptions and adaptation strategies, Reg. Environ. Change, 14, 1151$1162,2013$.

Gioli, G., Khan, T., Bisht, S., and Scheffran, J.: Migration as an adaptation strategy and its gendered implications: A case study from the Upper Indus Basin, Mount. Res. Develop., 34, 255-265, 2014.

Godde, P. M., Price, M. F., and Zimmermann, F. M. (Eds.): Tourism and Development in Mountain Regions, CABI Publishing, New York, USA, 2000.

Goodall, S. K.: Rural-to-Urban Migration and Urbanization in Leh, Ladakh: A Case Study of Three Nomadic Pastoral Communities, Mount. Res. Develop., 24, 220-227, 2004.

Gray, C. L.: Environment, Land, and Rural Out-migration in the Southern Ecuadorian Andes, World Develop., 37, 457-468, 2009.

Gray, C. L. and Bilsborrow, R. E.: Environmental Influences on Human Migration in Rural Ecuador, Demography, 50, 1217-1241, 2013.

Gray, C. L. and Bilsborrow, R. E.: Consequences of out-migration for land use in rural Ecuador, Land Use Policy, 36, 182-191, 2014.

Hahn, M. B., Riederer, A. M., and Foster, S. O.: The Livelihood Vulnerability Index: A pragmatic approach to assessing risks from climate variability and change - A case study in Mozambique, Global Environ. Change, 19, 74-88, 2009.

Hasson, S., Lucarini, V., Khan, M. R., Petitta, M., Bolch, T., and Gioli, G.: Early 21 st century snow cover state over the western river basins of the Indus River system, Hydrol. Earth Syst. Sci., 18, 4077-4100, doi:10.5194/hess-18-4077-2014, 2014.

Hirsch Hadorn, G., Hoffmann-Riem, H., Biber-Klemm, S., Grossenbacher-Mansuy, W., Joye, D., Pohl, C., Wiesmann, U., and Zemp, E.: Handbook of Transdisciplinary Research, Springer, Dordrecht, the Netherlands, 2008.

HM Treasury: The Stern Review of the Economics of Climate Change, HM Treasury, London, UK, 2006.

Ho, R. and Milan, A.: Where the Rain Falls Project Case Study Report Peru, Report no. 5, United Nations University Institute for Environment and Human Security (UNU-EHS), Bonn, Germany, 88 pp., 2012.

Hock, R.: Temperature index melt modelling in mountain areas, J. Hydrol., 282, 104-115, 2003.

Hugo, G.: Environmental concerns and international migration, Int. Migrat. Rev., 30, 105-131, 1996.

IPCC - Intergovernmental Panel on Climate Change: Climate change: Impacts, Adaptation and Vulnerability, Cambridge University Press, Cambridge, UK, 2007. 
IPCC - Intergovernmental Panel on Climate Change: Climate Change 2013: The Physical Science Basis, in: Contribution of Working Group I to the Fifth Assessment Report of the Intergovernmental Panel on Climate Change, edited by: Stocker, T. F., Qin, D., Plattner, G.-K., Tignor, M., Allen, S. K., Boschung, J., Nauels, A., Xia, Y., Bex, V., and Midgley, P. M., Cambridge University Press, Cambridge, UK and New York, USA, 1535 pp., 2013.

IPCC - Intergovernmental Panel on Climate Change: Climate Change 2014: Impacts, Adaptation, and Vulnerability, Part A: Global and Sectoral Aspects, in: Contribution of Working Group II to the Fifth Assessment Report of the Intergovernmental Panel on Climate Change, edited by: Field, C. B., Barros, V. R., Dokken, D. J., Mach, K. J., Mastrandrea, M. D., Bilir, T. E., Chatterjee, M., Ebi, K. L., Estrada, Y. O., Genova, R. C., Girma, B., Kissel, E. S., Levy, A. N., MacCracken, S., Mastrandrea, P. R., and White, L. L., Cambridge University Press, Cambridge, UK and New York, USA, 1132 pp., 2014.

Janssen, M. and Ostrom, E.: Empirically based, agent-based models, Ecol. Soc., 11, 37, 2006.

Jodha, N. S.: Mountain perspective and sustainability: a framework for development strategies, in: Sustainable Mountain Agriculture, edited by: Jodha, N. S., Banskota, M., and Partap, T., Oxford and IBH Publishing Co, New Delhi, India, 1992.

Kaenzig, R.: Can glacial retreat lead to migration? A critical discussion of the impact of glacier shrinkage upon population mobility in the Bolivian Andes, Populat. Environ., 36, 480-496, 2015.

Kälin, W.: From the Nansen Principles to the Nansen Initiative, Forced Migrat. Rev., 41, 48-49, 2012.

Khattak, M. S., Babel, M. S., and Sharif, M.: Hydro-meteorological trends in the upper Indus River basin in Pakistan, Clim. Res., 46, 103-119, 2011.

Klein, J. T., Grossenbacher-Mansuy, W., Häberli, R., Bill, A., Scholz, R. W., and Welti, M.: Transdisciplinarity: Joint Problem Solving among Science. An Effective Way for Managing Complexity, Birkhäuser Verlag, Basel, Switzerland, 332 pp., 2001.

Kniveton, D. R., Schmidt-Verkerk, K., Smith, C. D., and Black, R.: Climate change and migration: Improving methodologies to estimate flows, IOM Migration Research Series 33, International Organization for Migration, Geneva, Switzerland, 2008.

Kniveton, D. R., Smith, C. D., and Wood, S.: Agent based model simulations of future changes in migration flows for Burkina Faso, Global Environ. Change, 21, S34-S40, 2011.

Kniveton, D. R., Smith, C. D., and Black, R.: Emerging migration flows in a changing climate in dryland Africa, Nat. Clim. Change, 2, 444-447, 2012.

Kollmair, M. and Banerjee, S.: Drivers of migration in mountainous regions of the developing world: A review, Foresight: Migration and global environmental change driver review 9, Government Office for Science, London, UK, 2011.

Kollmair, M. and Gamper, S.: The sustainable livelihood approach: Training input, Development Study Group Zurich (DSGZ), Zurich, Switzerland, 2002.

Loschmann, C. and Siegel, M.: The influence of vulnerability on migration intentions in Afghanistan, Migrat. Develop., 3, 142$162,2014$.

Massey, D. S., Axinn, W. G., and Ghimire, D. J.: Environmental Change and Out-Migration: Evidence from Nepal, Populat. Environ., 32, 109-136, 2010.
McAdam, J. (Ed.): Climate change and displacement: Multidisciplinary perspectives, Bloomsbury Publishing, Oxford, UK, 2010.

McLeman, R.: Developments in modelling of climate changerelated migration, Climatic Change, 117, 599-611, 2012.

McLeman, R. and Smit, B.: Migration as an adaptation to climate change, Climatic Change, 76, 31-53, 2006.

Messerli, B., Viviroli, D., and Weingartner, R.: Mountains of the world: vulnerable water towers for the 21 century, Ambio, 13, 29-34, 2004.

Milan, A. and Ho, R.: Livelihood and migration patterns at different altitudes in the Central Highlands of Peru, Clim. Develop., 6, 6976, 2014.

Milan, A. and Ruano, S.: Rainfall variability, food insecurity and migration in Cabricán, Guatemala, Clim. Develop., 6, 61-68, 2014.

Mortreux, C. and Barnett, J.: Climate change, migration and adaptation in Funafuti, Tuvalu, Global Environ. Change, 19, 105-112, 2009.

Murali, J. and Afifi, T.: Rainfall variability, food security and human mobility in the Janjgir-Champa district of Chhattisgarh state, India, Clim. Develop., 6, 28-37, 2014.

Myers, N.: Environmental refugees in a globally warmed world, Bioscience, 43, 752-761, 1993.

Myers, N.: Environmental refugees, Populat. Environ., 19, 167182, 1997.

Myers, N.: Environmental refugees: a growing phenomenon of the 21st century, Philos. T. Roy. Soc. Lond. B, 357, 609-613, 2002.

Nicholls, R. J.: Coastal flooding and wetland loss in the 21 st century: changes under the SRES climate and socio-economic scenarios, Global Environ. Change, 14, 69-86, 2004.

Nicholson, C.: Climate change and the politics of causal reasoning: the case of climate change and migration, Geograph. J., 180, 151-160, 2014.

Nightingale A. J.: Warming up the climate change debate: A challenge to policy based on adaptationl, J. Forest Livelih., 8, 84-89, 2009.

Obokata, R., Veronis, L., and McLeman, R.: Empirical research on international environmental migration: a systematic review, Populat. Environ., 36, 111-135, 2014.

Onta, N. and Resurreccion, B. P.: The Role of Gender and Caste in Climate Adaptation Strategies in Nepal, Mount. Res. Develop., 31, 351-356, 2011.

Piguet, E.: Linking climate change, environmental degradation and migration: A methodological overview, Wiley Interdisciplinary Reviews, Climate Change, 1, 517-524, 2010.

Piguet, E.: Migration: The drivers of human migration, Nat. Clim. Change, 2, 400-401, 2012.

Piguet, E.: From "primitive migration" to "climate refugees": The curious fate of the natural environment in migration studies, Ann. Assoc. Am. Geogr., 103, 148-162, 2013.

Pounds, J. A., Fogden, M. P., and Campbell, J. H.: Biological response to climate change on a tropical mountain, Nature, 398, 611-615, 1999.

Rademacher-Schulz, C., Afifi, T., Warner, K., Rosenfeld, T., Milan, A., Etzold, B., and Sakdapolrak, P.: Rainfall variability, food security and human mobility: An approach for generating empirical evidence, Intersections No. 10, United Nations University Institute for Environment and Human Security (UNU-EHS), Bonn, Germany, 2012. 
Rademacher-Schulz, C., Schraven, B., and Mahama, E. S.: Time matters: shifting seasonal migration in Northern Ghana in response to rainfall variability and food insecurity, Clim. Develop., 6, 46-52, 2014.

Sakdapolrak, P., Promburom, P., and Reif, A.: Why successful in situ adaptation with environmental stress does not prevent people from migrating? Empirical evidence from Northern Thailand, Clim. Develop., 6, 38-45, 2014.

Siegel, M. and Waidler, J.: Migration and multi-dimensional poverty in Moldovan communities, East. J. Eur. Stud., 3, 105119, 2012.

Skeldon, R.: Population Pressure, Mobility, and Socio-Economic Change in Mountainous Environments: Regions of Refuge in Comparative Perspective, Mount. Res. Develop., 5, 233-250, 1985.

Smethurst, D.: Mountain Geography, Geogr. Rev., 90, 35-56, 2000.

Smith, C. D.: Modelling migration futures: development and testing of the Rainfalls Agent-Based Migration Model - Tanzania, Clim. Develop., 6, 77-91, 2014.

Smith, C. D., Kniveton, D., Wood, S., and Black, R.: Predictive Modelling, Forced Migrat. Rev., 31, 58-59, 2008.

Stark, O. and Bloom, D. E.: The new economics of labour migration, Am. Econ. Rev., 75, 173-178, 1985.

Stark, O. and Levhari, D.: On migration and risk in LDC, Econ. Develop. Cult. Change, 31, 191-196, 1982.

Suhrke, A.: Environmental degradation and population flows, J. Int. Affairs, 47, 473-496, 1994.

Tacoli, C.: Crisis or adaptation? Migration and climate change in a context of high mobility, Environ. Urban., 21, 513-525, 2009.

Tegart, W. J. McG., Sheldon, G. W., and Griffiths, D. C. (Eds.): Report prepared for Intergovernmental Panel on Climate Change (IPCC) by Working Group II, Australian Government Publishing Service, Canberra, Australia, 1990.

Umezaki, M. and Ohtsuka, R.: Changing Migration Patterns of the Huli in the Papua New Guinea Highlands: A Genealogical Demographic Analysis, Mount. Res. Develop., 22, 256-262, 2002.
USAID - United States Agency for International Development: Pakistan Education Statistics. Islamabad, Pakistan: Academy of Educational Planning and Management, http://www.aepam.edu.pk/Files/EducationStatistics/ PakistanEducationStatistics2010-11.pdf (last access: 15 February 2014), 2011.

Van der Geest, K., Khoa, N. V., and Thao, N. K.: Migration in the Upper Mekong Delta, Vietnam: What role for climate-related stressors?, Asia-Pacific Populat. J., 29, 25-41, 2015.

Verma, R., Nellemann, C., and Hislop, L.: Women at the Frontline of Climate Change: Gender Risks and Hopes, United Nations Environment Programme, GRID-Arendal, Arendal, Norway, 2011.

Viviroli, D., Dürr, H. H., Messerli, B., Meybeck, M., and Weingartner, R.: Mountains of the world, water towers for humanity: Typology, mapping, and global significance, Water Resour. Res., 43, W07447, doi:10.1029/2006WR005653, 2007.

Warner, K.: Environmental change and migration: methodological considerations from ground-breaking global survey, Populat. Environ., 33, 3-27, 2011a.

Warner, K.: Interdisciplinary approaches to researching environmental change and migration: Methodological considerations and field experiences from the EACH-FOR project, in: Handbook of Research Methods in Migration, Castles, S., Cohen, R., Delgado-Wise, R., and DeWind, J., Edward Elgar Publishing Ltd, Cheltenham, UK, 366-395, 2011 b.

Warner, W. and Afifi, T.: Where the rain falls: Evidence from 8 countries on how vulnerable households use migration to manage the risk of rainfall variability and food insecurity, Clim. Develop., 6, 1-17, 2014.

Warner, K. and van der Geest, K.: Loss and damage from climate change: local-level evidence from nine vulnerable countries, Int. J. Global Warm., 5, 367-386, 2013.

Wrathall, D. J.: Migration amidst social-ecological regime shift: The search for stability in Garifuna villages of northern Honduras, Human Ecol., 40, 583-596, 2012. 